\title{
DONA FERNANDA E A TÉCNICA NARRATIVA DE QUINCAS BORBA
}

\section{MARIA CECÍLIA BOECHAT}

Universidade Federal de Minas Gerais

Belo Horizonte, Minas Gerais, Brasil

Resumo: Uma das questões colocadas pela recepção crítica do romance Quincas Borba diz respeito à interpretação de uma de suas personagens secundárias, dona Fernanda. O trabalho pretende retomar os termos da questão e avançar a discussão, explicitando a dupla função que essa personagem exerce na narrativa, dotando o romance de um forte elemento de compaixão em relação ao protagonista do romance, Rubião, mas também representando um limite a esse sentimento. Com isso, pretende-se relacionar a personagem com a técnica narrativa de Machado de Assis, no que apresenta de especificidade neste romance.

Palavras-chave: Quincas Borba; dona Fernanda; técnica narrativa.

\section{DONA FERNANDA AND THE NARRATIVE TECNIQUE IN QUINCAS BORBA}

Abstract: One of the issues raised by the critical reception of Machado's novel Quincas Borba, is the analysis of Dona Fernanda, one of its secondary characters. This paper intends to advance that discussion by focusing on the character's double role of providing compassion and the limits thereof in relation to the protagonist, Rubião. In this respect, the point of the paper is to associate the secondary character with Machado de Assis's narrative technique in the specific context of the novel discussed.

Keywords: Quincas Borba; dona Fernanda; narrative technique. 
U: $\mathrm{m}$ amplo e sintético quadro da recepção crítica da obra de Machado de Assis encontra-se em um aparentemente despretensioso ensaio de Antonio Candido intitulado "Esquema de Machado de Assis". E aí se encontra, também, uma das mais refinadas formulações sobre a obra do autor, na medida que percebe e elabora sua "matriz formal", definida, de modo preciso e sucinto, como a técnica de "sugerir as coisas mais tremendas da maneira mais cândida" - uma técnica por ele denominada "técnica de espectador" e descrita nos seguintes termos:

E o mais picante é o estilo guindado e algo precioso com que trabalha, e que se de um lado pode parecer academismo, de outro sem dúvida parece uma forma sutil de negaceio, como se o autor estivesse rindo um pouco do leitor. Estilo que mantém uma espécie de imparcialidade, que é a marca pessoal de Machado, fazendo parecer duplamente intensos os casos estranhos que apresenta com moderação despreocupada. Não é nos apaixonados naturalistas de seu tempo, teóricos da objetividade, que encontramos o distanciamento estético que reforça a visão da realidade, mas sim na sua técnica de espectador.

A partir dessa matriz formal, que se poderia chamar o "tom machadeano", é que podemos compreender a profundeza e a complexidade de uma obra lúcida e desencantada, que esconde as suas riquezas mais profundas. Como Kafka e como Gide, ao contrário de Dostoiévski, Proust ou Faulkner, os tormentos do homem e as iniquidades do mundo aparecem nele sob um aspecto nu e sem retórica, agravados pela imparcialidade estilística acima referida. (CANDIDO, 1977, p. 22)

Tal como a expõe Antonio Candido, portanto, a técnica machadiana diz respeito não somente ao tratamento do narrador e da linguagem - ambos distanciados, avessos ao sentimentalismo -, como também à relação estabelecida entre essas instâncias e o drama desenvolvido pelo enredo. Nos termos do crítico: "os casos estranhos", apresentados nos enredos, ou "os tormentos do homem e as iniquidades do mundo" aparecem "agravados pela imparcialidade estilística" (CANDIDO, 1977, p. 22, grifo nosso).

Daí, então, ser possível afirmar, reelaborando os termos da formulação, que a matriz machadiana pode ser compreendida como uma técnica de contraste - entre a impassibilidade do narrador, de acordo com a tradição realista da narrativa em terceira pessoa, e a intensidade do drama vivido pelas personagens. O termo aparece no parágrafo seguinte do ensaio: 
A sua técnica consiste essencialmente em sugerir as coisas mais tremendas da maneira mais cândida (como os ironistas do século XVIII); ou em estabelecer um contraste entre a normalidade social dos fatos e a sua anormalidade essencial, ou em sugerir, sob aparência do contrário, que o ato excepcional é normal, e anormal seria o ato corriqueiro. (CANDIDO, 1977, p. 23, grifo nosso)

Entretanto, dentre os romances da chamada "fase madura" do autor, Quincas Borba talvez seja um caso a ser detalhado, pois, ainda que mantendo a imparcialidade do narrador, neste romance o texto parece estabelecer uma aproximação maior em relação ao protagonista, uma percepção maior do seu sofrimento. Um registro dessa especificidade deixa-se entrever nesse mesmo ensaio de Antonio Candido, no comentário que fecha uma breve paráfrase do enredo:

No romance Quincas Borba, um modesto professor primário, Rubião, herda do filósofo Quincas Borba uma fortuna [...]. A sua fortuna se dissolve em ostentação e no sustento de parasitas [...]. No fim, pobre e louco, ele morre abandonado; mas em compensação, como queria a filosofia do Humanitismo, Palha e Sofia estão ricos e considerados, dentro da mais perfeita normalidade social. Os fracos e os puros foram sutilmente manipulados como coisas e em seguida são postos de lado pelo próprio mecanismo da narrativa, que os cospe de certo modo e se concentra nos triunfadores, acabando por deixar no leitor uma dúvida sarcástica e cheia de subentendidos: o nome do livro designa o filósofo ou o cachorro, o homem ou o animal, que condicionaram ambos o destino de Rubião? Este começa como simples homem, chega na sua loucura a julgar-se imperador e acaba como um pobre bicho, fustigado pela fome e a chuva, no mesmo nível que o seu cachorro. (CANDIDO, 1977, p. 29)

Assim, para evidenciar o contraste entre a trajetória ascendente do casal e aquela degradante do protagonista, o crítico, de uma escrita em geral muito sóbria, dotada de invejável contenção, lança mão de uma expressão de afeto, que se deixa escapar: "[Rubião]", como diz, "acaba como um pobre bicho, fustigado pela fome e a chuva, no mesmo nível que o seu cachorro" (CANDIDO, 1977, p. 29, grifo nosso). ${ }^{1}$

\footnotetext{
${ }^{1}$ Embora aqui não explorada, a identificação entre Rubião e seu cão Quincas Borba, cujo efeito é registrado por Antonio Candido, é um dos elementos que poderiam ser chamados nesta discussão, a fim de evidenciar mecanismos agenciados pela narrativa para ressaltar o drama vivido pelo protagonista.
} 
Quincas Borba, diferentemente do que ocorre nos outros romances que tiveram seus narradores ressaltados pelos estudos críticos (em Memórias póstumas de Brás Cubas, nos termos de Roberto Schwarz, a volubilidade de um narrador que revela a desfaçatez de uma classe social; em Dom Casmurro, na esteira de Helen Caldwell, a ironia de um narrador não confiável) -, embora não destoando da matriz machadiana, parece ter evocado, sobretudo, o próprio drama de Rubião. Efeito que não tardaria a ser percebido, pois, como indica José Luiz Passos, parece ter sido José Veríssimo, dez anos após a publicação do romance, o primeiro a registrá-lo:

Primeiramente, notemos que Quincas Borba guarda uma notável diferença quando comparado aos demais romances machadianos. Dez anos depois de sua publicação, resenhando Dom Casmurro, José Veríssimo se lamentava, sutil e laconicamente, de que Machado tivesse voltado, com o narrador Bento Santiago, ao mesmo tom de Brás Cubas, quando ele, o crítico, tinha visto em Quincas Borba o gérmen de algo novo, de "uma humanidade maior, uma realidade mais viva." Nenhum outro protagonista goza dessa humanidade chã do telúrico Pedro Rubião de Alvarenga. (PASSOS, 2007, p. 166) ${ }^{2}$

Tomando-se esses poucos, mas importantes, comentários como uma percepção válida do romance já se pode afirmar que de algum modo, ainda não totalmente explicitado, o drama de Rubião parece, senão maior, mais "sentido" ou mais agravado do que o de Brás Cubas ou o de Dom Casmurro. E isso, a despeito das alterações feitas na passagem do folhetim ao romance, que expurgou da primeira versão os excessos sentimentalistas - como observa John Gledson a respeito de muitas dessas alterações, elas evidenciariam um movimento de "dessentimentalização" que é "coerente com o tom apropriado dos dois tipos de publicação, de folhetim e de livro" (GLEDSON, 2011).

Não é difícil, portanto, comprovar o distanciamento do narrador de Quincas Borba; vários episódios poderiam ser chamados a fazê-lo e alguns até podem ser considerados antológicos. É o caso da cena da morte de Rubião, da qual certamente saímos marcados pela imagem de um delirante Rubião a cingir uma coroa imaginária na cabeça e pelo mordaz comentário que fecha o curto capítulo, em que o narrador, anotando que "a morte é séria", termina referindo-se à morte de Rubião de modo jocoso: "dous minutos de agonia, um

${ }^{2} \mathrm{O}$ trecho de José Veríssimo aí citado encontra-se em: VERÍSSIMO, José. Um irmão de Braz Cubas: O Dom Casmurro do Sr. Machado de Assis. In: __ Estudos de literatura brasileira. Ed. Oscar Mendes. São Paulo; Belo Horizonte: Edusp; Itatiaia, 1977. v. 3, p. 25. 
trejeito horrível, e estava assinada a abdicação" (ASSIS, 1988, p. 268, grifo nosso).

Entretanto, em uma análise estilística desse capítulo, Evanildo Bechara surpreende, na própria descrição do gesto de Rubião, um movimento inverso, de "apelo à simpatia do leitor":

[...] diz-nos Machado de Assis, no Quincas Borba, que Rubião, julgandose "imperador dos franceses" no momento da agonia, cingiu a "coroa", que não era sequer uma bacia, "onde pudesse palpar a ilusão", "ele pegou nada, ergueu nada e cingiu nada". O emprego de nada depois do verbo sem se completar com um não antes do verbo é uma maneira anômala de expressar a negação verbal em português. E é um traço estilístico: não porque seja exclusivamente pessoal de Machado de Assis (quem nos garante que outrem já não o tenha feito? - nem o escritor faz isso sistematicamente), mas porque nesse dado contexto, o emprego de nada nessas condições tem um valor "estético", fazendo-nos ver dolorosamente o gesto do pobre louco mercê do tratamento de nada não como mera partícula negativa, mas como um substantivo negativo - o oposto de alguma coisa: a emoção do escritor e o seu apelo à nossa simpatia se comunicam através desse emprego de nada [...]. (BECHARA, 1968, p. 427-428)

Se a ironia resultante do contraste entre o "assunto sério" e o modo de seu tratamento, mais próximo do cômico, é evidente, a inversão dos termos flagrada por Bechara (o apelo à necessária percepção da tragicidade da cena para a composição irônica) é preciosa, corroborando a necessidade de atentarmos para outros possíveis procedimentos da narrativa usados com a mesma intenção - de apelo à nossa simpatia. É o caso, certamente, da identificação entre Rubião e o cachorro Quincas Borba, como já sugerido por Antonio Candido. Na mesma perspectiva, o retorno a uma recorrente discussão crítica de imediato se impõe.

Muito já se chamou atenção para o problema representado, em relação à visão de mundo machadiana, por uma das personagens secundárias do romance, dona Fernanda. Trata-se de uma das senhoras da seleta sociedade carioca escolhidas por Sofia para compor uma comissão de ajuda humanitária, a Comissão das Alagoas. Ela é apresentada no capítulo CXVIII do romance:

[...] Dona Fernanda, esposa de um deputado [...] tinha pouco mais de trinta anos, era jovial, expansiva, corada e robusta; nascera em Porto 
Alegre, casara com um bacharel das Alagoas, deputado agora por outra província, e, segundo corria, prestes a ser ministro de Estado. A naturalidade do marido foi o pretexto para metê-la na comissão; e bem acertado foi, porque ela pedia como quem manda, não tinha acanhamento nem admitia recusa. (ASSIS, 1988, p. 176)

Mais à frente, no mesmo capítulo, é traçado o seu retrato moral: "Dona Fernanda possuía, em larga escala, a qualidade da simpatia; amava os fracos e os tristes, pela necessidade de os fazer ledos e corajosos. Contavam-se dela muitos atos de piedade e dedicação" (ASSIS, 1988, p. 178). Se no retrato avulta sua capacidade de compaixão ("possuía, em larga escala, a qualidade da simpatia; amava os fracos e os tristes"), esta ainda parece ser garantida apenas pela voz da opinião. Suas ações, porém, não a desmentem. No mesmo capítulo, por longas horas dona Fernanda escuta as confidências de Benedita, e nos informa a narrativa que as escutou, não apenas com grande atenção e interesse, mas até "comovida" (ASSIS, 1988, p. 179). No capítulo seguinte, é ao marido que consola, de modo que, "Ao almoço, já ele sorria, ainda que de um sorriso pálido" (ASSIS, 1988, p. 182). O trecho se alonga um pouco mais, contando que ela conversa com o marido sobre outros temas para desviá-lo de suas preocupações, até conseguir de fato mudar seu estado de espírito. Nessa toada chegamos ao fechamento do episódio, que merece atenção, pois, pouco antes do registro da mudança alcançada em relação ao estado de espírito do marido, encontramos a seguinte exclamação, a respeito de dona Fernanda: "Pia criatura!" Em seguida, o fio do enredo é retomado: "Teófilo, entendendo a mulher, ia-se fazendo alegre [...]" (ASSIS, 1988, p. 182).

A exclamação parece ser de Teófilo e é coerente que o seja, mas não se apresenta em discurso direto. No caso do uso do discurso indireto livre, porém, como observa John Wood, "vemos coisas através dos olhos e da linguagem do personagem, mas também através dos olhos e linguagem do autor" (WOOD, 2011, p. 25, grifo nosso). Neste caso, a própria narrativa (não o narrador $)^{3}$ é que estaria legitimando, garantindo o caráter compassivo de dona Fernanda, e esse detalhe justificaria a interpretação de que a personagem, por sua bondade e seu altruísmo, seria atípica no universo machadiano. Posição discordante, entretanto, conta já com uma tradição crítica importante.

${ }^{3} \mathrm{O}$ pressuposto teórico, aqui, é o da necessária distinção entre narrador e autor implícito. Como observa Oscar Tacca: "Essa entidade a que chamamos 'autor' surge muitas vezes na obra, por detrás do narrador, não confiando inteiramente nele, arranjando, compondo, aclarando, acrescentando, completando" (TACCA, 1983, p. 19). A respeito da instância do autor implícito no caso específico do romance de Machado de Assis, ver Silva (2011). 
Ingrid Stein (1984), em estudo monográfico sobre as personagens femininas de Machado de Assis, após observar a tendência crítica até então dominante ("Dona Fernanda [...] é festejada pela quase totalidade dos críticos como mulher bondosa e caridosa" [STEIN, 1984, p. 109]), levanta suspeitas quanto a essa representação, na esteira de John Kinnear ( $1977^{4}$ apud STEIN, 1984, p. 109), que, sendo à época exceção, defendera "a opinião de que na prática do bem pela personagem entra uma boa dose de autoglorificação e autocontemplação da própria bondade" (KINNEAR, 1977, apud STEIN, p. 109). Segundo Stein, "Machado de Assis não construiu essa figura como uma personagem pura e simplesmente bondosa. Antes, com ela, nos induz a refletir sobre os processos psicológicos que, neste caso específico, a levaram a esse comportamento" (STEIN, 1984, p. 111-112).

A polêmica, levantada, ao que parece, pelo crítico inglês na década de 1970, entretanto, estaria longe de se esgotar aí. Trinta anos depois, em 2007, José Luiz Passos, em estudo também dedicado às personagens de Machado de Assis, retoma a primeira posição, reafirmando ser dona Fernanda "uma das poucas [personagens] que escapam ao crivo de sua ironia" (PASSOS, 2007, p. 163). Em 2011, John Gledson retoma a posição contrária, afirmando, incisivamente, que a personagem, "tão bondosa em aparência", teria "enganado a maioria dos críticos". ${ }^{5}$ No mesmo ano, Ana Cláudia Suriani da Silva pondera as posições:

$\mathrm{O}$ mesmo princípio que relativiza nosso julgamento se aplica à única personagem que poderíamos colocar acima de qualquer suspeita no romance: Dona Fernanda. Sob esse ângulo, mesmo a bondade de Dona Fernanda pode ser relativa. Na verdade, já existe na fortuna crítica uma pequena tradição de estudos sobre Dona Fernanda, que defendem ou desmentem a sua bondade imanente. [...] Acredito no entanto que Dona Fernanda não é nem bondosa por natura nem tão-pouco age movida somente por interesse próprio. Seu altruísmo é antes simples exercício da liberdade limitada de uma mulher dependente (como todas as do romance, menos talvez a comadre Angélica de Barbacena), da qual, na sua posição social e como sinal de status, espera-se que se preocupe com o próximo, com os mais pobres e desprotegidos. (SILVA, 2011)

\footnotetext{
${ }^{4}$ KINNEAR, John C. The Role of Dona Fernanda in Machado de Assis' novel "Quincas Borba". Aufzätze zur portugiesischen Kulturgeschichte, n. 14, p. 118-130, 1977.

5 Segue o trecho na íntegra: "O tom irônico e cínico do romance refinou-se lentamente, e em conjunção com o enredo - a Comissão e a personagem de dona Fernanda são, de certa maneira, o fecho de ouro da sua construção. Esta senhora, de fato, tão bondosa em aparência que enganou a maioria dos críticos, é outra que acende charutos nas desgraças alheias, só que os dela são mais refinados que os de Sofia, como convém a tão 'conspícua dama'" (GLEDSON, 2011).
} 
Como se pode perceber, se existem essas vertentes de interpretação, é porque a narrativa oferece argumentos a ambas, de modo que a própria fortuna crítica configura os termos do problema colocado pela personagem.

Por um lado, e segundo a primeira hipótese, de autenticidade de seu caráter, ela funcionaria, no romance, como contrapeso a Sofia, tal como estabelecera, em 1964, Augusto Meyer:

Em contrapeso à figura de Sofia, Machado põe de pé outra personagem feminina cheia de encanto, uma das poucas mulheres equilibradas que temperam de saúde e graça a amargura um tanto opressiva dos seus romances: a gaúcha Fernanda, Nanã, animosa, casamenteira, sadia, tão cheia de vida em contraste com o nervoso Teófilo, seu marido. Fernanda e a Dona Carmo do Memorial, como a pálida Flora de Esaú e Jacó, escaparam às garras de sua ironia, resguardadas numa espécie de nicho. (MEYER, 1964, p. 188)

Por outro lado, esse contraste, funcional e coerente em relação à técnica adotada no romance, é relativizado pela narrativa, em uma cena que mostra que, embora capaz e mesmo fortemente dotada do sentido da compaixão, a personagem não adere totalmente a esse sentimento. Trata-se de uma visita feita à casa de Rubião, quando ele já se encontra internado para tratamento, ocasião em que, enquanto Sofia chega a se sufocar por se encontrar em meio à pobreza e à sujeira, temos acesso aos pensamentos piedosos de dona Fernanda:

Sem que nenhuma recordação pessoal the viesse daquela miserável estância, sentia-se presa de uma comoção particular e profunda, não a que dá a ruína das cousas. Aquele espetáculo não lhe trazia um tema de reflexões gerais, não lhe ensinava a fragilidade dos tempos, nem a tristeza do mundo; dizia-lhe tão somente a moléstia de um homem, de um homem que ela mal conhecia, a quem falara algumas vezes. E ia ficando e olhando, sem pensar, sem deduzir, metida em si mesma, dolente e muda. Sofia não ousava articular nada, com receio de ser desagradável a tão conspícua dama. Tinham ambas os vestidos apanhados, para evitar a mácula da poeira; mas Sofia acrescentou a essa precaução a agitação viva, contínua e impaciente da ventarola, como pessoa que sufocasse naquela atmosfera. Chegou a tossir algumas vezes. (ASSIS, 1988, p. 260) 
É importante ressaltar o detalhe da cena, a qual, mantendo o contraste entre as duas personagens, todavia não as opõe totalmente, uma vez que o gesto de dona Fernanda, que também recolhe a barra do vestido, restringe seu sentimento de compaixão, impondo-lhe uma limitação. "Tinham ambas os vestidos apanhados, para evitar a mácula da poeira": assim, embora dona Fernanda se aproxime do drama de Rubião, mantém certo distanciamento; o texto evita, deste modo, qualquer excesso de sentimentalismo e imprime, senão uma mácula no retrato moral de dona Fernanda, certamente maior complexidade em sua configuração. ${ }^{6}$

A bem dizer, a personagem que estabelece o contraste puro com a sordidez de Sofia (e do mundo) seria a comadre Angélica, que, em Barbacena, acolhera, sem segundas intenções nem reservas, primeiramente o cão (que fora despachado de casa, quando Rubião ainda não se dera plenamente conta da cláusula da herança) e que, ao final do romance, agasalha e alimenta o já enlouquecido Rubião e seu cachorro. ${ }^{7}$ Personagem plana, tipificada, a comadre faz jus ao nome (provavelmente motivado) e é em sua casa que o protagonista falece, sob seus cuidados, em contraste com os olhos de "antigos desafetos", que prazerosamente testemunham sua loucura (ASSIS, 1988, p. 268).

Proximidade compassiva ou impassibilidade e mesmo prazer na desgraça alheia: assim se constituem os polos dos modos previstos pela narrativa de compreensão ou recepção da história de vida de Rubião, tal como fica enunciado no último e também antológico capítulo do romance:

... Eia! Chora os dous recentes mortos, se tens lágrimas. Se só tens riso, ri-te! É a mesma cousa. O Cruzeiro, que a linda Sofia não quis fitar, como lhe pedia Rubião, está assaz alto para não discernir os risos e as lágrimas dos homens. (ASSIS, 1988, p. 269)

Já a terceira posição aí desenhada, impassível e olímpica ("assaz alto para não discernir os risos e as lágrimas"), não diz respeito à recepção, mas, mais propriamente, ao narrador do texto, que, com sua imparcialidade (nisso

\footnotetext{
${ }^{6}$ Esse modo de dotação de complexidade, por sua vez, pode ser melhor compreendido a partir da "estética do personagem" que Paul Dixon reconhece nos contos de Machado de Assis, "menos baseada na [ideia da] pessoa em si e mais relacionada à noção da interação ou 'jogo' entre as pessoas", ou, em outros termos, "mais a ver com a relação entre seres ('o contraste entre dous caracteres') do que com a construção de indivíduos convincentes" (DIXON, 2006, p. 202).

${ }^{7}$ A personagem passou quase despercebida pela polêmica, à exceção de Ana Cláudia Suriani, que chega a inseri-la na discussão. Ao explicar o comportamento compassivo de dona Fernanda pelo ajuste a seu papel social, Suriani deixa entrever o deslocamento da questão, observando justamente que, em meio às mulheres dependentes do romance, que têm sua liberdade limitada pelas convenções sociais, a exceção poderia caber à comadre Angélica. Cf. p. 137 deste ensaio, em que o trecho é citado na íntegra.
} 
de acordo com a tradição oitocentista das narrativas realistas em terceira pessoa), "faz parecer duplamente intensos os casos estranhos que apresenta com moderação despreocupada." (CANDIDO, 1977, p. 260). Entretanto, no que diz respeito à recepção, a narrativa coloca em representação uma terceira posição, de meio-termo, ocupada justamente por dona Fernanda, que, assim, representaria uma espécie de "leitor ideal", reunindo, no mesmo tipo de recepção, a adesão e o distanciamento criados pela narrativa.

Pois, por meio de dona Fernanda, e por um momento, antes que ela recolha a saia, o romance efetivamente apela à nossa simpatia, permitindo que o drama de Rubião seja visto não com a lente distanciada das "reflexões gerais", do tema filosófico da condição humana ou do tema social da redução do homem a objeto ou coisa, mas em sua condição particular, ou seja, que vejamos somente "a moléstia de um homem, de um homem [é o texto que, significativamente, repete a expressão] que ela mal conhecia, a quem falara algumas vezes" (ASSIS, 1988, p. 260). A configuração de dona Fernanda, enfim, é capaz de evocar o efeito mais amplo e específico do romance - sua "maior humanidade", nos termos de José Veríssimo. Sem perda, porém, da necessária contraparte da equação.

Para finalizar, caberia lembrar que Augusto Meyer, o primeiro a estudar as alterações do texto do folhetim para o romance, já anotara que justamente dona Fernanda foi um dos alvos da "intuição cirúrgica" do escritor - a personagem teve cortado, na forma final, o "caloroso elogio" que lá lhe fora feito (MEYER, 1964, p. 174), de maneira de fato um tanto exagerada para o equilibrado romance.

\section{Referências}

ASSIS, Machado de. Quincas Borba. Estabelecimento do texto e notas de Adriano da Gama Kury. Rio de Janeiro; Belo Horizonte: Livraria Garnier, 1988.

BECHARA, Evanildo. Noções elementares de estilística. In: Moderna Gramática Portuguesa. 13. ed. São Paulo: Companhia Editora Nacional, 1968. p. 425431.

CANDIDO, Antonio. Esquema de Machado de Assis. In: Vários escritos. 2. ed. São Paulo: Duas Cidades, 1977. p. 13-32.

DIXON, Paul. Modelos em movimento: os contos de Machado de Assis. Teresa Revista de Literatura Brasileira, São Paulo, n. 6/7, p. 185-206, 2006.

GLEDSON, John. Quincas Borba: um romance em crise. Machado de Assis em Linha - Revista Eletrônica de Estudos Machadianos, Rio de Janeiro, v. 4, n. 8, p. 29-50, 
dez. 2011. Disponível em: <http://machadodeassis.fflch.usp.br >. Acesso em: 18 abr. 2018.

MEYER, Augusto. Quincas Borba em variantes. In: _. A chave e a máscara. Rio de Janeiro: O Cruzeiro, 1964. p. 171-189.

PASSOS, José Luiz. Machado de Assis: o romance com pessoas. São Paulo: Edusp; Nankin Editorial, 2007.

SILVA, Ana Cláudia Suriani da. Retórica ficcional de Quincas Borba. Floema, Caderno de teoria e história literária, Vitória da Conquista, n. 9, jul./dez. 2011. Disponível em: <http://periodicos.uesb.br/index.php/floema/article/viewFile/ 2766/2463>. Acesso em: 18 abr. 2018.

STEIN, Ingrid. Figuras femininas em Machado de Assis. Rio de Janeiro: Paz e Terra, 1984.

TACCA, Oscar. As vozes do romance. Coimbra: Livraria Almedina, 1983.

WOOD, James. Como funciona a ficção. Trad. Denise Bottmann. São Paulo: Cosac Naify, 2011.

MARIA CECÍLIA BOECHAT é professora (Adjunto IV) de Literatura Brasileira na Faculdade de Letras da UFMG, doutora em literatura comparada pela mesma instituição e teve sua tese publicada em 2003 (Paraísos artificiais: o romantismo de José de Alencar e sua recepção crítica. Editora UFMG). Em 2009, obteve Pós-doutorado junto à UNESP, campus de Araraquara, com uma pesquisa sobre origens do conto e do romance românticos e atualmente realiza seu segundo Pós-doutorado, junto à UERJ, sobre o romance de Aluísio Azevedo. Desde o Doutorado, tem dedicado seus estudos e pesquisas à história da prosa moderna no Brasil. Sobre a obra de Machado, publicou esparsa e ocasionalmente - um artigo, intitulado "A chinela turca: Machado e a tradição folhetinesca" (0 eixo e a roda: revista de literatura brasileira, Belo Horizonte, v. 19, n. 2, p. 87-94, 2010) e tem preparado, aguardando no prelo, um capítulo de livro sobre as relações entre Casa de pensão e Quincas Borba, romance este que é aqui retomado. Email: cboechat@letras.ufmg.br

Recebido: 10.07.2018

Aprovado: 29.09.2018 